\title{
Analysis of the Magnetization Mechanism of an Nd-Fe-B HDDR Magnet by Measurement of Recoil Curves
}

\author{
T. Maki and S. Hirosawa \\ NEOMAX Co., Ltd., 2-15-17 Egawa, Shimamoto-cho, Mishima-gun, Osaka 618-0013, Japan
}

\begin{abstract}
The magnetization mechanism of an Nd-Fe-B HDDR magnet was studied by measuring its recoil curves. When compared with those of isotropic Nd-Fe-B sintered, HDDR, and melt-spun magnets, the behavior of the recoil curves of the HDDR magnet was similar to that of the recoil curves of the melt-spun magnet. This means that the isotropic HDDR magnet behaved like single-domain particles. In addition, calculated isotropic recoil curve that assumes only rotation of the magnetization of single-domain particles showed the same tendency as the recoil curves of the HDDR magnet. This result indicates that the recoil curves of an isotropic HDDR magnet were dominated by rotation of the magnetization, and were not significantly influenced by domain wall movement. Moreover, the recoil curve of an anisotropic HDDR magnet behaved similarly to calculated anisotropic recoil curve based on the rotation of the magnetization of single-domain particles with an orientation distribution. This means that the recoil curves of an anisotropic HDDR magnet were also dominated by rotation of the magnetization. These results suggest that the HDDR magnet behaved like single-domain particles in its recoil curves, which were dominated by rotation of the magnetization and were not significantly influenced by domain wall movement.
\end{abstract}

Key words: $\mathrm{HDDR}$, magnetization mechanism, $\mathrm{Nd}_{2} \mathrm{Fe}_{14} \mathrm{~B}$, recoil curve, rotation of the magnetization

\section{リコイルカーブを用いた Nd-Fe-B 系 HDDR 磁粉の磁化過程解析}

\author{
槙 智仁・広沢 哲
}

株式会社N E OMA X，大阪府三島郡島本町江川 2-15-17（†618-0013）

\section{1. はじめに}

$\mathrm{Nd}-\mathrm{Fe}-\mathrm{B}$ 系 HDDR 磁粉は $0.3 \mu \mathrm{m}$ 程度の微細な結晶粒を 有しており 1),2), 磁粉状態で高保磁力が得られること, 異方 性化が可能であることから異方性ボンド磁石用磁粉として 広く用いられている。 Nd-Fe-B 系材料の主相である $\mathrm{Nd}_{2} \mathrm{Fe}_{14} \mathrm{~B}$ 化合物は単磁区となる臨界粒径が $0.3 \mu \mathrm{m}$ 以下と 計算されており 3),4)，HDDR 磁粉の結晶粒径が単磁区臨界 粒径付近であることからその磁区構造が多磁区であるか単 磁区であるかははっきりしていない，Uehara らは $\mathrm{Nd}-\mathrm{Fe}-\mathrm{B}$ 系 HDDR 磁粉の磁区構造をローレンツ顕微鏡に よって観察し，熱消磁状態においては結晶粒内に磁壁が存 在することを報告している 5)。しかしながら，組織観察に おいては試料作製中の加工劣化とそれに伴う磁区構造変化 の可能性が否定できないこと，観察が局所的であるため磁 粉全体の状態を表しているとは限らないといった問題点が ある。

本論文では $\mathrm{Nd}-\mathrm{Fe}-\mathrm{B}$ 系 HDDR 磁粉の磁化機構解析方法 の一つとして減磁曲線のリコイルカーブに着目した．減磁 曲線のリコイルカーブはVSM で測定できるため加工劣化 の心配がなく，その測定結果は組織観察に比心゙磁粉全体の 特性を表していると考えられる，具体的には，まず等方性 において $\mathrm{Nd}-\mathrm{Fe}-\mathrm{B}$ 系 HDDR 磁粉と他の $\mathrm{Nd}-\mathrm{Fe}-\mathrm{B}$ 系材料 （焼結磁石および超急冷磁粉）のリコイルカーブ比較を行 い，その後これらの測定結果とモデル計算によるリコイル カーブとの比較を行った。続いて異方性を有する場合の HDDR 磁粉のリコイルカーブを測定し，等方性 HDDR 磁
粉およびモデル計算との比較を行った

\section{2. 実験方法}

試料は等方性試料として $\mathrm{Nd}-\mathrm{Fe}-\mathrm{B}$ 系等方性焼結磁石, 等 方性 HDDR 磁粉および超急冷磁粉の 3 種類, 異方性試料 として Nd-Fe-B 系異方性 HDDR 磁粉を用意した。各試料 の主な特徴を Table 1 に示す．等方性焼結磁石は $3 \mathrm{~mm}$ 角 のものを用意した. HDDR 磁粉および超急冷磁粉は直径 $300 \mu \mathrm{m}$ 以下の球状粉末および扁平状粉末をパラフィンで 固めて VSM 用試料とした。なお等方性試料については磁 界配向を行わず, 異方性試料については $1200 \mathrm{kA} / \mathrm{m}$ の磁界 中で配向させた. 減磁曲線のリコイルカーブ測定にはVSM を用いて行った. 試料を $4800 \mathrm{kA} / \mathrm{m}$ のパルス磁界にて着磁 した後, $40 \mathrm{kA} / \mathrm{m}$ 刻みでリコイルカーブを測定した．VSM における最大印加磁界は $1600 \mathrm{kA} / \mathrm{m}$ とし, 測定結果に対し 反磁界補正は行わなかった。

Table 1 Characteristics of samples.

\begin{tabular}{|c|c|c|c|c|}
\hline & $\begin{array}{c}\text { Sample } \\
\text { magnet }\end{array}$ & $\begin{array}{c}\text { Rare-earth } \\
\text { content } \\
(\mathrm{at} \%)\end{array}$ & $\begin{array}{c}\text { Grain } \\
\text { size } \\
(\mu \mathrm{m})\end{array}$ & $\begin{array}{c}\text { Coercivity } \\
(\mathrm{kA} / \mathrm{m})\end{array}$ \\
\hline \hline \multirow{3}{*}{ Isotropic } & Sintered & 14.0 & 5 & 1196 \\
\cline { 2 - 5 } & HDDR & 12.8 & 0.3 & 1255 \\
\cline { 2 - 5 } & Melt-spun & 13.2 & 0.05 & 1307 \\
\hline Anisotropic & HDDR & 12.8 & 0.3 & 1236 \\
\hline
\end{tabular}




\section{3. 結果}

\section{1 等方性の場合}

$\mathrm{Nd}-\mathrm{Fe}-\mathrm{B}$ 系等方性焼結磁石，等方性 HDDR 磁粉および超 急冷磁粉の 3 試料についてリコイルカーブ測定を行った結 果をFig. 1 に示す.各リコイルカーブの挙動に着目すると, 等方性焼結磁石のリコイルカーブは下に凸の曲線である一 方, 等方性 HDDR 磁粉および超急冷磁粉のリコイルカーブ は直線的な挙動を示していることがわかる．焼結磁石（結 晶粒径約 $5 \mu \mathrm{m}$ ）が多磁区粒子，超急冷磁粉（結晶粒径約 $0.05 \mu \mathrm{m} ）$ が単磁区粒子の挙動を示していると考えると, HDDR 磁粉のリコイルカーブ挙動は単磁区的挙動である 可能性がある.

リコイルカーブ挙動の違いについてさらに調查するため, 単磁区粒子の磁化回転を用いてリコイルカーブのモデル計 算を行った。なお，本論文では粒子間相互作用の影響につ いては考慮していない. Fig. 2 に磁化回転モデルの模式図
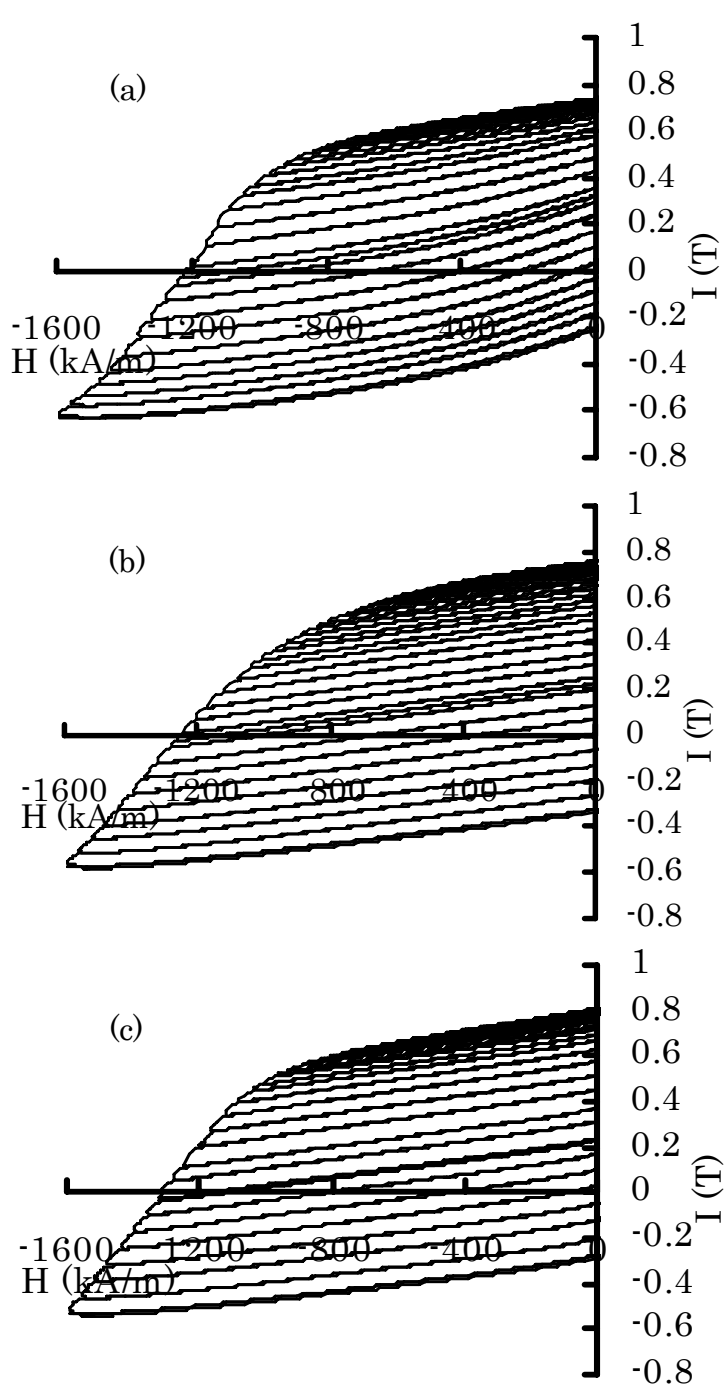

Fig. 1 Recoil curves of isotropic (a) sintered, (b) HDDR, and (c) melt-spun magnets.
を示す。一軸磁気異方性の容易軸方向に対し角度 $\theta_{0}$ の方向 に磁界 $H$ を印加すると, 磁化 $I_{\mathrm{S}}$ は $H$ に対し角度 $\theta$ の方向に 回転する。

この状態でのエネルギー $E$ は

$$
E=-K_{u} \cos ^{2}\left(\theta-\theta_{0}\right)-I_{s} H \cos \theta .
$$

と表せる．ここで $K_{\mathrm{u}}$ は一軸異方性定数である． $I_{\mathrm{s}}$ の方向が 安定となるのは $E$ が極小のときであるから

$$
\frac{\partial E}{\partial \theta}=K_{u} \sin 2\left(\theta-\theta_{0}\right)+I_{s} H \sin \theta=0 .
$$

を解くことで $\theta$ 救まる。ここで式(2)を変形し $I_{S} H / 2 K_{\mathrm{u}}=$

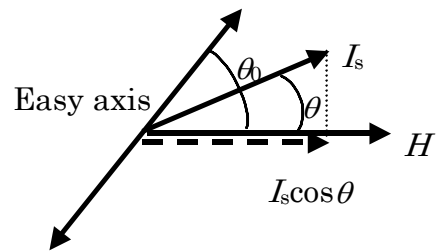

Fig. 2 Rotation of the magnetization from the easy axis due to application of a magnetic field.

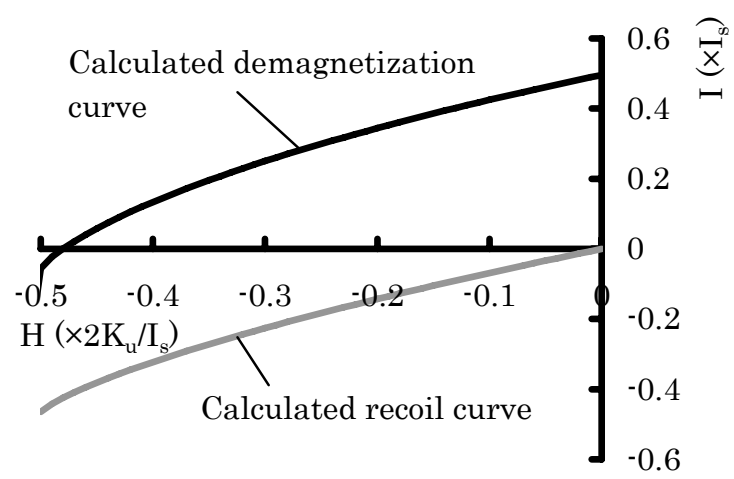

Fig. 3 Calculated isotropic demagnetization curve and recoil curve.

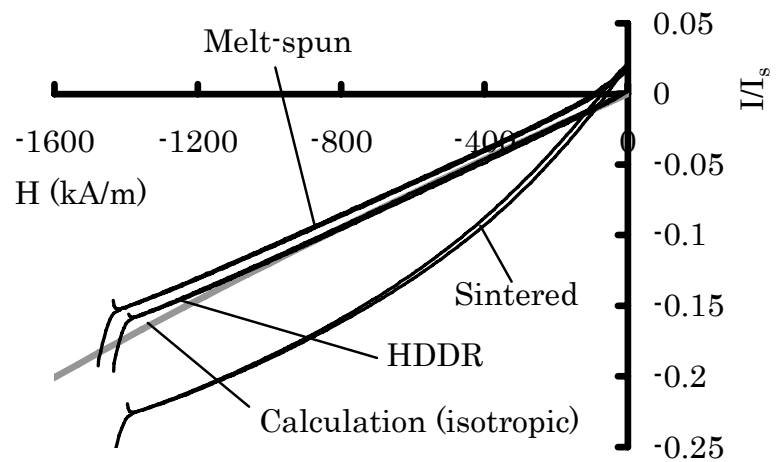

Fig. 4 Comparison of the measured recoil curves of isotropic sintered, HDDR, and melt-spun magnets and the calculated isotropic recoil curve. 
H’おくと

$$
\frac{1}{2} \sin 2\left(\theta-\theta_{0}\right)+H^{\prime} \sin \theta=0 .
$$

となる. この式を数值的に解くことにより，与えられた $\theta_{0}$ の值に対応した $\theta$ を求めた.

任意の $H^{\prime}$ および $\theta_{0}$ のとき， $I_{\mathrm{S}}$ の磁界方向成分 $I$ は

$$
I=I_{s} \cos \theta \text {. }
$$

で表される，完全着磁後の等方性減磁曲線を得るには磁化 が $\theta_{0}=0 \sim 90^{\circ}$ の範囲に均一に分布していると考え，

$$
I=\int_{0^{\circ}}^{90^{\circ}} I_{s} \cos \theta \cdot 2 \pi \sin \theta_{0} \cdot d \theta_{0} .
$$

を計算することで Fig. 3 実線に示す減磁曲線を得た.

ここまでの計算はStoner-Wohlfarth の手法 ${ }^{6)}$ と同様であ る. 得られた減磁曲線に対し $\mathrm{Nd}_{2} \mathrm{Fe}_{14} \mathrm{~B}$ 化合物の物性值 $K_{\mathrm{u}}$ $\left.=4.5 \mathrm{MJ} / \mathrm{m}^{3}, \quad I_{\mathrm{S}}=1.61 \mathrm{~T}^{3}\right)$ を導入した場合, 保磁力の值は 約 $2700 \mathrm{kA} / \mathrm{m}$ となる. しかしながら, 用いた試料の保磁力 は Table 1 に示したように $H_{\mathrm{cJ}}=1200 \sim 1300 \mathrm{kA} / \mathrm{m}$ と計算 值の $1 / 2$ 以下である. 計算によるリコイルカーブを得るに は一部の粒子が不可逆磁化反転した段階で磁界を取り除い たときの曲線を計算する必要があるが, 保磁力の計算值と 測定值に差があることから考えると, Stoner-Wohlfarth の 手法と同様な一斉回転による不可逆磁化反転を仮定するこ とは適切でないと考えられる。そこで，不可逆磁化反転は 低角度の $\theta_{0}$ から不連続的に起こると仮定し 7$), \theta_{0}=0 \sim 45^{\circ}$ にある磁化が既に不可逆磁化反転した状態から $H^{\prime}=-0.5$ 〜0で減磁曲線を描いた。 これにより Fig. 3 に示す計算に よるリコイルカーブ (等方性) を得た.

Fig. 4 に，等方性 3 試料において原点付近を通るリコイ ルカーブおよび計算によるリコイルカーブ (等方性) を比 較した図を示す.磁化回転モデルにおける粒子の $K_{1}$ は一様 であると考え, $\mathrm{Nd}_{2} \mathrm{Fe}_{14} \mathrm{~B}$ 化合物の物性值 $K_{\mathrm{u}}=4.5 \mathrm{MJ} / \mathrm{m}^{3}$, $\left.I_{\mathrm{s}}=1.61 \mathrm{~T}^{3}\right)$ を用いて計算を行った. また測定試料の反磁 界を厳密に求めるのは困難であるため，本報告では磁化回 転モデルに対し反磁界を反磁界係数 $\mathrm{N}=0.333$ として加え た. 計算結果と比較すると HDDR 磁粉および超急冷磁粉の リコイルカーブは挙動がほぼ一致し, 焼結磁石は低磁界に おける磁束密度の増加が計算結果に比べ大きいことが明ら かとなった.このことから HDDR 磁粉および超急冷磁粉の リコイルカーブは磁化回転が支配的であり，磁壁の移動が 含まれない挙動であると考えられる. 一方結晶粒径約 $5 \mu \mathrm{m}$ の等方性焼結磁石のリコイルカーブ挙動は磁化回転のみで は説明できず，多磁区粒子であるためリコイルカーブに磁 壁移動が含まれていると考えられる.

\section{2 異方性の場合}

ここまでは等方性試料を用いて結晶粒径の異なる材料で 比較を行ったが, 次に HDDR 磁粉において異方性を有する 試料のリコイルカーブについて調査を行った. Fig. 5 に

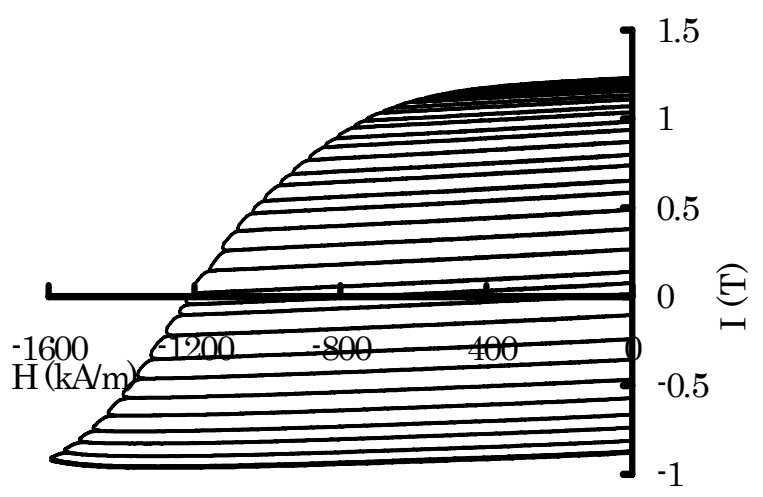

Fig. 5 Recoil curve of an anisotropic HDDR magnet.

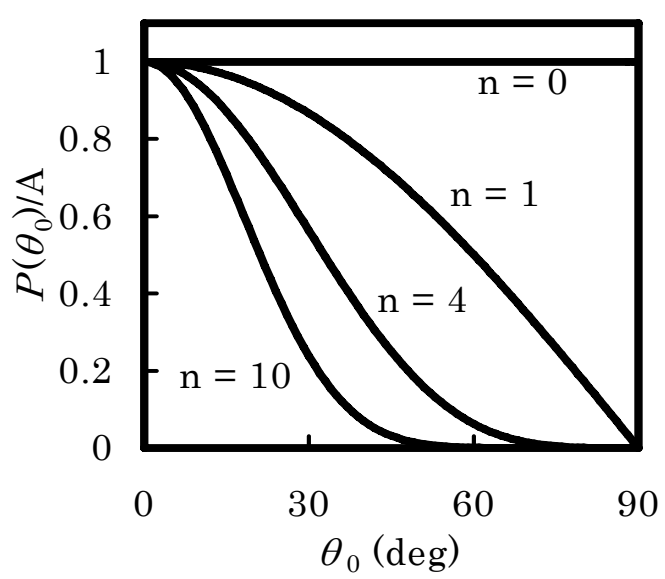

Fig. 6 Relationship between the orientation distribution $P\left(\theta_{0}\right)$ and $\theta_{0}$.

異方性 HDDR 磁粉のリコイルカーブ測定結果を示す. 異方 性 HDDR 磁粉においてもリコイルカーブの挙動は直線的 であった．また，異方性 HDDR 磁粉のリコイル透磁率は等 方性 HDDR 磁粉に比べて明らかに小さいことがわかる.

異方性 HDDR 磁粉においても単磁区粒子の磁化回転モ デルとの比較を行うため, 異方性の場合のリコイルカーブ を計算した，異方性を表現するため，角度 $\theta_{0}$ における配向 分布を定義する. $\theta_{0}$ の存在確率 $P\left(\theta_{0}\right)$ を

$$
P\left(\theta_{0}\right)=A \cos ^{n} \theta_{0} .
$$

とおくと（ $A$ は規格化因子 $), \mathrm{n}$ が大きくなるにつれて $\theta_{0}$ の存在確率は低角度側が大きくなるため (Fig. 7), 磁化が 容易軸方向に配向している状態を表現できる. 配向分布を 導入したときの磁化の值は式(5)から

$$
I=\int_{0^{\circ}}^{90^{\circ}} P\left(\theta_{0}\right) I_{s} \cos \theta \cdot 2 \pi \sin \theta_{0} \cdot d \theta_{0} .
$$

となる. 例として $\mathrm{n}=4$ における減磁曲線を等方性減磁曲 線 $(\mathrm{n}=0)$ とともに Fig. 7 に示す. 配向分布導入により磁 化が増加しており，異方性化した状態が表現された。

続いて，配向分布を導入した場合について等方性の場合 
と同様にリコイルカーブの計算を行った. $\mathrm{n}=4$ において $\theta_{0}$ $=0 \sim 27^{\circ}$ の磁化が既に不可逆磁化反転していると仮定す ると, Fig. 7 に示すように異方性の場合の原点付近を通る リコイルカーブが得られた．このリコイル透磁率を等方性 の場合と比較すると，実際の測定結果と同様に計算モデル においても異方性の場合にはリコイル透磁率が小さくなる ことが分かった。

Fig. 8 に, 異方性 HDDR 磁粉の原点付近を通るリコイル カーブおよび計算によるリコイルカーブ（異方性）を比較 した図を示す。等方性の場合と同様，モデル計算には $\mathrm{Nd}_{2} \mathrm{Fe}_{14} \mathrm{~B}$ 化合物の物性值を導入し反磁界補正を行った. 両 者の挙動はほぼ一致しており, 等方性の場合と同様な結果 であった. 従って, 異方性の場合においても HDDR 磁粉の リコイルカーブには磁壁移動が含まれず, 磁化回転が支配 的であるといえる.

さらに Fig. 4 および Fig. 8 からは, 配向分布を導入した 計算モデルが等方性および異方性 HDDR 磁粉のリコイル

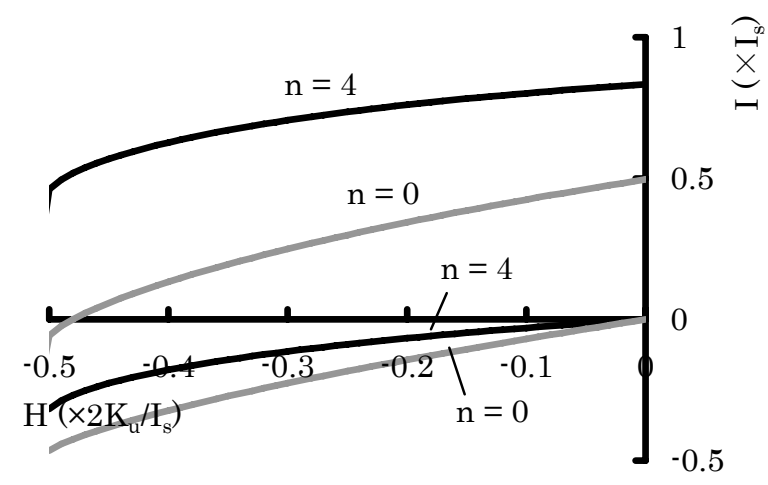

Fig. 7 Calculated isotropic and anisotropic demagnetization curves and recoil curves $(n=0$, 4).

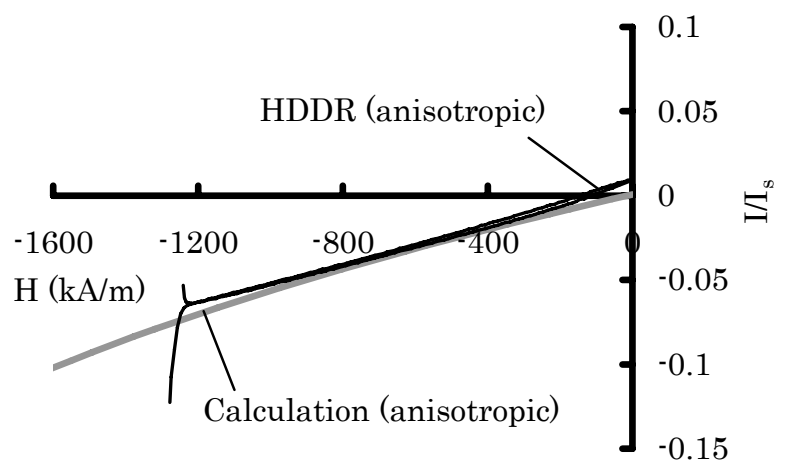

Fig. 8 Comparison of the measured recoil curve of an anisotropic HDDR magnet and the calculated anisotropic recoil curve.
カーブの透磁率の違いを表現できていることも読み取れる. 従って配向分布を導入した磁化回転モデルを用いることで, 異方化度の異なる HDDR 磁粉のリコイルカーブを表現で きることが明らかとなった。このことは計算に用いた配向 分布が実際の HDDR 磁粉の配向分布を表現する関数の一 つであることを示しており,リコイル測定を HDDR 磁粉の 配向分布評価に活用できると考えられる.

\section{4. まとめ}

等方性の場合において磁化回転モデルと $\mathrm{Nd}-\mathrm{Fe}-\mathrm{B}$ 焼結 磁石, HDDR 磁粉および超急冷磁粉のリコイルカーブを比 較した結果, モデルと HDDR 磁粉および超急冷磁粉は同様 な挙動を示したのに対し, 焼結磁石は低磁界における磁束 密度の増加が大きい結果となった.このことから HDDR 磁 粉のリコイルカーブには磁壁移動が含まれず, 磁化回転が 支配的であると考えられる。

異方性の場合においても磁化回転モデルと HDDR 磁粉 のリコイルカーブの形はほぼ一致していた. 従って, 異方 性の場合においても HDDR 磁粉のリコイルカーブには磁 壁移動が含まれず，磁化回転が支配的であるといえる.

また，配向分布を導入した磁化回転モデルを用いて HDDR 磁粉のリコイルカーブを表現できることが明らか になった。このことは計算に用いた配向分布が実際の HDDR 磁粉の配向分布を表現する関数の一つであること を示しており, 今後はリコイル測定を HDDR 磁粉の配向分 布評価に活用できると期待される.

\section{References}

1) T. Takeshita and R. Nakayama: Proceedings of 10th International Workshop on Rare-Earth Magnets and Their Applications at Kyoto, Vol. 1, 551 (1989).

2) T. Takeshita and R. Nakayama: Proceedings of 12th International Workshop on Rare-Earth Magnets and Their Applications at Canberra, 670 (1992).

3) M. Sagawa, S. Fujimura, H. Yamamoto, Y. Matsuura, S. Hirosawa and K. Hiraga: Proceedings of 4th International Symposium on Magnetic Anisotropy and Coercivity in Rare Earth-Transition Metal Alloys at Dayton, 587 (1985).

4) J. D. Livingston: J. Appl. Phys., 57, 4137 (1985).

5) M. Uehara, T. Tomida, H. Tomizawa, S. Hirosawa and Y. Maehara: J. Magn. Magn. Mater., 159, L304 (1996).

6) E. C. Stoner and E. P. Wohlfarth: Philos. Trans. R. Soc. London A, 240, 599 (1948).

7) H. Kronmüller, K. -D. Durst and M. Sagawa: J. Magn. Magn. Mater., 74, 291 (1988).

2006年10月19日受理，2007年3月19日採録 